\title{
Use of geographic indicators of healthcare, environment and socioeconomic factors to characterize environmental health disparities
}

\author{
Cindy M. Padilla ${ }^{1 *}$, Wahida Kihal-Talantikit ${ }^{2,3}$, Sandra Perez ${ }^{4}$ and Severine Deguen ${ }^{2,3}$
}

\begin{abstract}
Background: An environmental health inequality is a major public health concern in Europe. However just few studies take into account a large set of characteristics to analyze this problematic. The aim of this study was to identify and describe how socioeconomic, health accessibility and exposure factors accumulate and interact in small areas in a French urban context, to assess environmental health inequalities related to infant and neonatal mortality.

Methods: Environmental indicators on deprivation index, proximity to high-traffic roads, green space, and healthcare accessibility were created using the Geographical Information System. Cases were collected from death certificates in the city hall of each municipality in the Nice metropolitan area. Using the parental addresses, cases were geocoded to their census block of residence. A classification using a Multiple Component Analysis following by a Hierarchical Clustering allow us to characterize the census blocks in terms of level of socioeconomic, environmental and accessibility to healthcare, which are very diverse definition by nature. Relation between infant and neonatal mortality rate and the three environmental patterns which categorize the census blocks after the classification was performed using a standard Poisson regression model for count data after checking the assumption of dispersion.

Results: Based on geographic indicators, three environmental patterns were identified. We found environmental inequalities and social health inequalities in Nice metropolitan area. Moreover these inequalities are counterbalance by the close proximity of deprived census blocks to healthcare facilities related to mother and newborn. So therefore we demonstrate no environmental health inequalities related to infant and neonatal mortality.

Conclusion: Examination of patterns of social, environmental and in relation with healthcare access is useful to identify census blocks with needs and their effects on health. Similar analyzes could be implemented and considered in other cities or related to other birth outcomes.
\end{abstract}

Keywords: GIS, Healthcare accessibility, Environment, Infant mortality, Environmental health inequalities

\section{Background}

Geographical inequalities have become a major issue which guides policy development in Europe. The inhomogeneity of the environment on the territory, does not guarantee an equal access to an environment of quality [1]. In the same way, unequal distribution of people's exposure to - and potentially of disease resulting

\footnotetext{
* Correspondence: cindy.padilla@ehesp.fr

'Department of Quantitative Methods in Public Health, EHESP School of

Public Health, Sorbonne-Paris Cité, 35043 Rennes, France

Full list of author information is available at the end of the article
}

from - environmental conditions constitutes an important public health concern in Europe [2].

Reducing health inequalities involves the characterization and the identification of how factors accumulate and interact in an area. Certain socioeconomic groups bear a disproportionate burden of environmental externalities [3], and vulnerable to the health effects resulting from this exposition [4]. Previous studies have demonstrated that population with a low socioeconomic status tends to be more highly exposed to air pollutants and toxicants, due especially to their residential proximity to pollution sources 
(e.g. high-traffic roads, industrial facilities and waste disposal sites) [5-12]. Conversely, few have considered to wholesome environments may be related to urban socioeconomic inequalities [13] and have shown that access to green spaces may have a beneficial effect on health [14, 15].

Infant and neonatal mortality are highly sensitive measures which reflect economic development, general living conditions, social well-being and rates of illness of whole populations [16]. Moreover, they are recognized by the World Health Organization (WHO) as indicators of the health status of a population and of the effectiveness of the health care system [16]. Skilled assistance at delivery and access to emergency obstetric care are the most effective interventions to prevent these early and intra-partum related deaths [17]. This requires both the availability of such services as well as the will and the possibility for pregnant women to seek this care at delivery [18]. Recent research has considered that accessibility to health care facilities is known to influence health services usage [19] but the quality of life depends on the adequacy of their position in the territory [19, 20]. Most of these neonatal deaths occur during the first day of life and complications related to delivery care make up a large proportion of the overall neonatal mortality [21, 22]. Contextual factors, such as social and environmental exposures, are well-documented to be associated with adverse birth outcomes. Children's exposure to air pollution is therefore of primary concern [23], especially in reference to the life course approach which state that health problems during childhood have repercussions on health at later stages of life [24]. They are particularly sensitive to environmental factors such as teratogens agents, and early exposure to environmental factors can lead to diseases or subsequent severe functional deficits [25-27].

Previous studies demonstrated that the adequate location of healthcare facilities deserve careful and detailed future analysis. Geographical factors such as distance between home and healthcare facilities are part of the first and the second delay and suggested an influence on the choice of delivery place [18] as well as being related to neonatal mortality risks $[28,29]$. Some studies demonstrated that the usage of health services decreases with increasing distance between health facilities and families' homes. This also holds true in the case of accidental out-of-hospital births [30, 31]. In France, distance to the closest maternity unit was found to aggravate the risks of out-of-hospital birth [30].

Several factors hinder access to the health care services needed to avert maternal and newborn deaths and morbidity. These include perception of the mothers as cultural norms, attention to the needs of women in planning and delivering health services, previous experiences in the hospital [32], and individual factors or health behaviors of the mother as maternal age (teenage mothers and mothers aged 40 and over), multiple births, smoking habits, obesity, that could affect health outcomes [33].

Moreover, the health status of a given population is a result of complex interactions between the social and physical characteristics of their areas of residence (e.g. neighborhood socioeconomic status), environmental exposure factors and those that relate to the characteristics of the health care system and care practices. To our knowledge, no previous studies explored such a large variety of field to characterize neighborhood areas.

At the small area level, we view to identify the census blocks which cumulate environmental inequalities where public authorities should design relevant preventive actions in priority. In our context, we aim to identify through geographic indicators of healthcare, environment and socioeconomic factors, local territorial inequalities. The two majors objectives were : i) Identification and characterization of socioeconomic, health accessibility and exposure factors in order to explain how they accumulate and interact in an area. ii) Investigation the role of these three fields on environmental health inequalities related to infant and neonatal mortality.

\section{Methods}

\section{Study setting and geographical unit}

This ecological study setting in the Nice metropolitan area (MA), situated in Provence Alpes Côte d'Azur region, southern France. The geographical unit is the sub-municipal French census block called IRIS (Îlot Regroupé pour l'Information Statistique) defined by the National Institute of Statistics and Economic Studies (INSEE). It is the smallest administrative unit for which socioeconomic and demographic data are available in France. This geographical unit averages 2000 inhabitants and is constructed to be as homogenous as possible in terms of socio-demographic characteristics and land use. Nice MA has an approximate population of 537769 habitants in 2012 divided into 49 municipalities and 236 census blocks, for a total area of $1465,8 \mathrm{~km}^{2}$. Nice MA is composed by a majority of women compare to men; the specificity of the MA is that families with or without children leaved the Coast to the periphery, in search of a bigger housing environment with lesser cost. On the contrary, single-parent families or only people leave this space consisted mainly of individual housing to get closer to the Coast. Moreover, Nice MA is characterized by a heterogeneous distribution of the environment due to the geographic repartition of the MA. Whereas Nice is characterized by a dense urban area with an important traffic related urban pollution close to the littoral coast, conversely, the mountain part is sparse and the density of population is very low. 


\section{Geographical indicators}

The construction of geographic indicators is needed to identify and characterize at the census block level the level of; deprivation, environmental exposure and accessibility measure to healthcare facilities. They were calculated using the Geographical Information System (GIS) with ArcGIS version 9.1 (ESRI, Redlands, CA).

\section{Deprivation index}

This index used to characterize the socioeconomic dimensions have been defined and analyzed in previous studies in order to analyze environmental and health inequalities [12, 34-36].

The deprivation index built at the French census block level was developed by Lalloue et al in 2013 [37]. The index used multiple principal component analysis. It is constructed from 13 variables which come from the National Institute of Statistics and Economic Studies available variables. It is a cumulative index that combines different dimensions family structure, household type, immigration status, mobility, employment, income, education and housing.

\section{Environmental exposure "negative and positive"}

The high-traffic roads database and topographic database information was provided from the National Geographic Institute. Proximity to major roads with high traffic was determined as the proportion of residential building located within a specified distance of the hightraffic roads (minimum $70 \mathrm{~km} / \mathrm{h}$ ) in each census block [38]. More precisely, circles with radii of $150 \mathrm{~m}$ were created around each road segment according to the literature $[38,39]$. The measure of proximity was determined by select residential buildings located inside each circle which will be considered exposed to the hightraffic road and the measure for census block was obtained by dividing the total number of exposed residential building by the total building of the census block. Figure 1 presents the spatial distribution of the environmental exposure factors: major streets, census blocks who follow the $10 \mathrm{~m}^{2}$ of green space per habitant

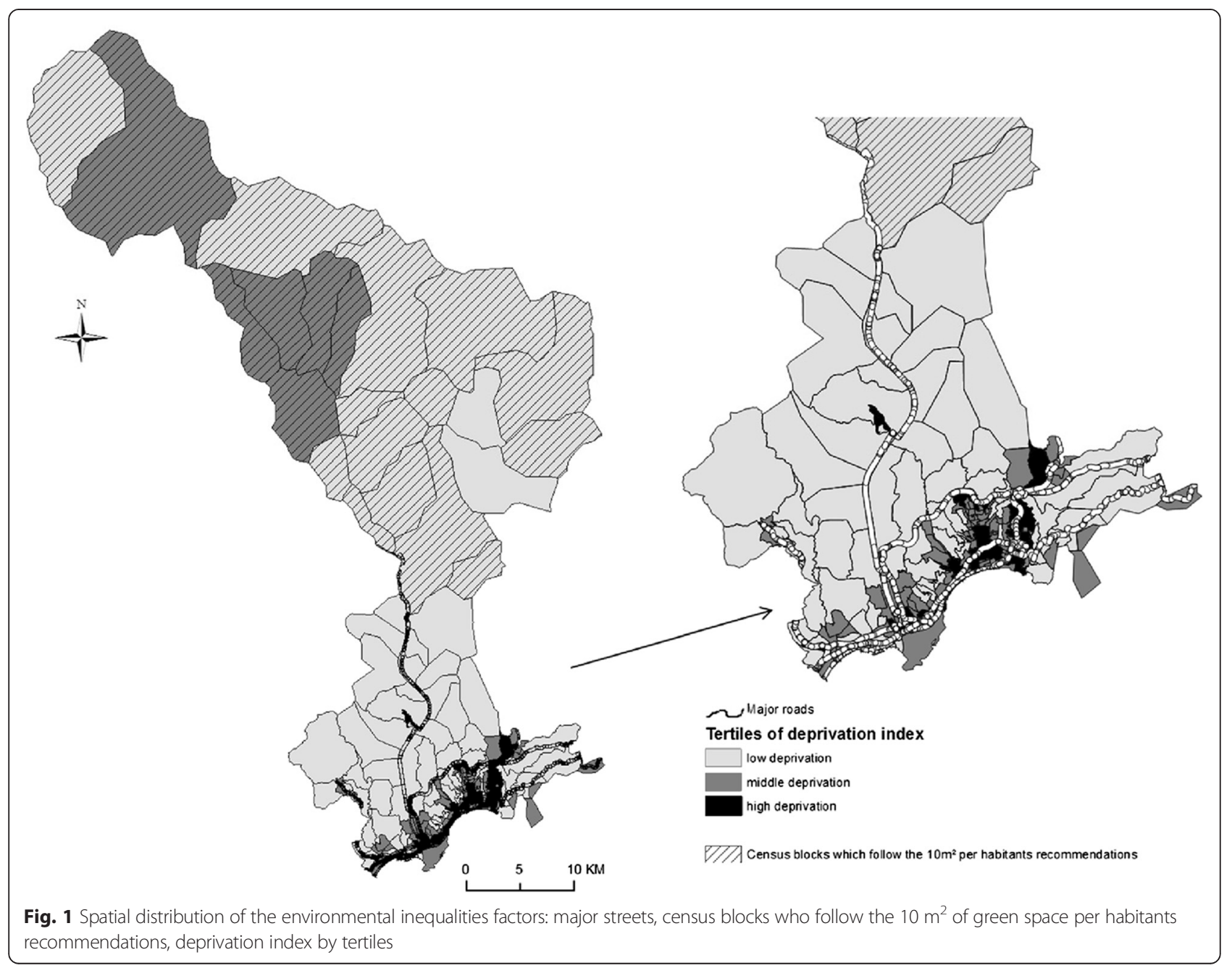


recommendations and the deprivation index by tertiles according to its distribution.

\section{Proximity to green space}

The green space databases were providing by the Corine Land Cover website [40]. The definition of green space included natural area (e.g. parks, forest, garden...); to not include pesticide in our green space definition, agricultural areas have not been taken into account. Two green space indicators have been created. The first indicator is defined by the proportion of the geographic area occupied by green spaces within the total area of a census block [41, 42]. The second indicator is defined according to the World Health Organization (WHO) guidelines which recommends at least $10 \mathrm{~m}^{2}$ of green space per habitant $[43,44]$.

\section{Accessibility to healthcare}

The present work focuses on the spatial dimensions accessibility and availability to healthcare service. Spatial accessibility refers to the distance to the nearest healthcare service whereas spatial availability is defined as the amount of healthcare services available in a predefined area. First, the proximity indicator was defined as the road network distance (measured in meters and in minutes) to the closest healthcare service related to the mother (gynecologist, midwives and hospital center with a specialized service for pregnant women) and the same indicator related to newborn (pediatricians and hospital center with a specialized service for newborn). Second, the availability indicator is defined as the medical density which represents the number of healthcare service within the female population of reproductive age of the census block.

\section{Quantification of mortality impacts}

Neonatal and infant mortality are defined as the number of babies who died during their first month and their first year of life per 1000 live births that occurred during this time period, respectively. Cases were collected from death certificates in the city hall of each municipality in the Nice MA. Using the parental postal addresses, cases were geocoded to their census block of residence using ArcGIS version 9.1 (ESRI, Redlands, CA). The French data protection authority (CNIL) approved the study (number: 911149v1). Figure 2 illustrates the spatial distribution of number of cases of infant and neonatal deaths by tertiles at the census blocks level of Nice MA.

\section{Statistical analysis}

In our ecological study, to be robust in the following statistical analysis, one of the main features is to measure the degree of interdependence between located observations. We use basic statistical analysis after checking that spatial autocorrelation is no statistically significant (data not shown). Analyses of correlations between geographic indicators were performed using Spearman's Correlation test after proving the nonnormal distribution of these indicators.

Firstly, we create a classification using a Multiple Component Analysis (MCA) following by a hierarchical clustering. This methodology allow us to characterize the census blocks in terms of environmental patterns according to level of socioeconomic, environmental and accessibility to healthcare, which are very diverse definition by nature. MCA analysis is one of the most popular dimensionality reduction methods dealing with categorical variables. The MCA method permits to take variable collinearity into account, thereby avoiding redundant information. Hierarchical clustering is frequently used after MCA [45] in data mining to create meaningful categories. A distance between elements (usually the Euclidian distance) and a distance between categories are defined. Thanks to the Ward's distance, this algorithm allows to obtain homogeneous categories in their composition and heterogeneous between them (i.e. with maximum between-categories inertia). These analyses were made with FactoMineR, a $\mathrm{R}$ package dedicated to multivariate Exploratory Data Analysis [46].

Secondly, we performed a standard Poisson regression model for count data after checking the assumption of overdispersion. We examined the relation between infant and neonatal mortality rate and the three environmental patterns which categorize the census blocks after the classification. All analyses were conducted using STATA, Statistical Software: Release 13. College Station, TX: StataCorp LP.

\section{Results}

We identified three environmental patterns according to environmental exposure, deprivation and accessibility to healthcare. The percentage of variance explained by the two first components is $39 \%$. Figure 3 present the spatial distribution of the census blocks according to their profiles. The environmental pattern 1 represents census blocks faced environmental inequalities but with favorable accessibility of healthcare and transportation networks. The higher and some middle deprived census blocks faced higher proximity to high-traffic roads and lower proportion to green space related to the census blocks surface and the WHO recommendations. However, these census blocks have higher availability and a very easy accessibility of healthcare and very good transportation networks. The environmental pattern 2 represents census blocks exposed to a mixture of positive and negative factors which balance each other. This class is composed by some higher and all the middle deprived census blocks who lived close to high-traffic roads but 


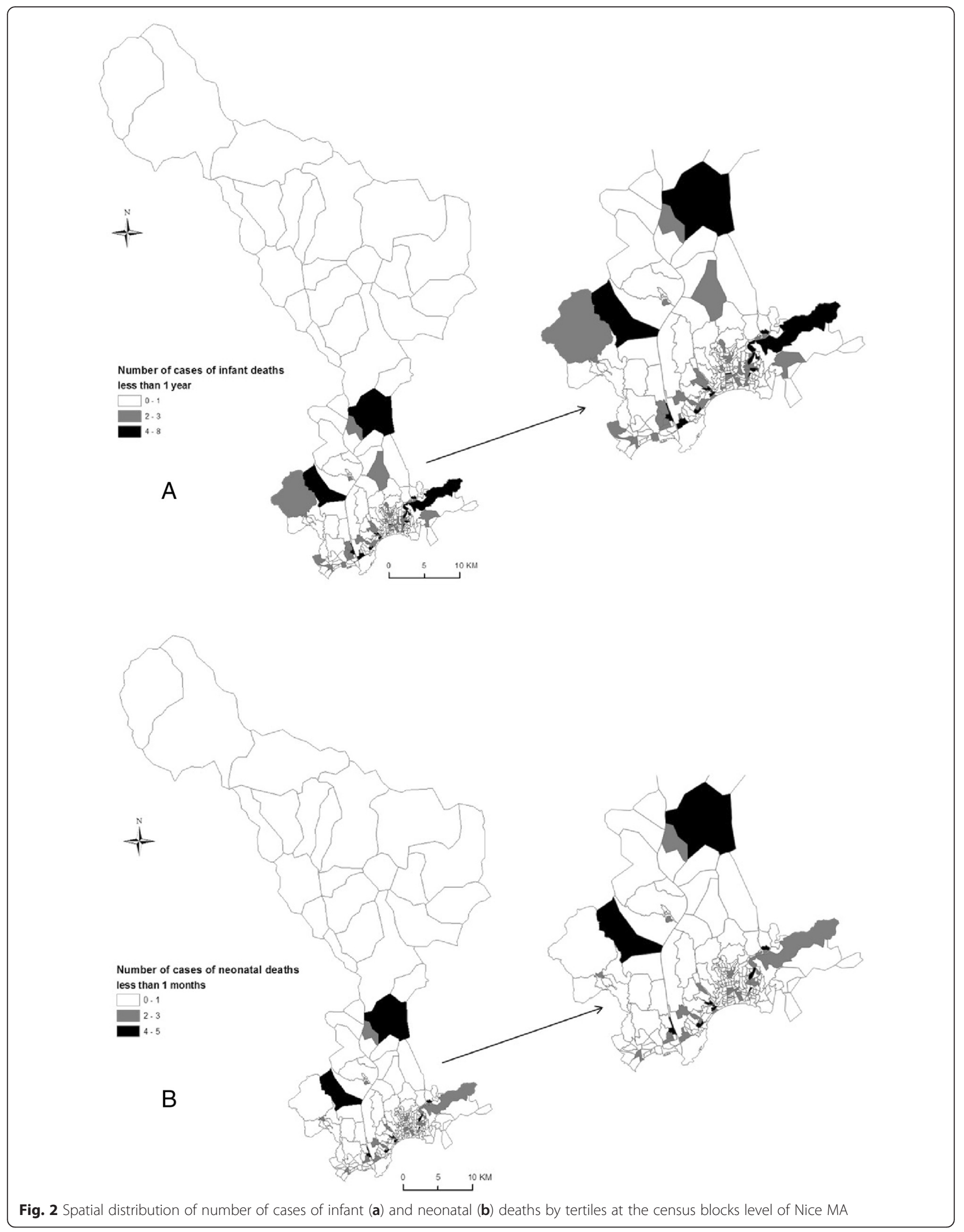




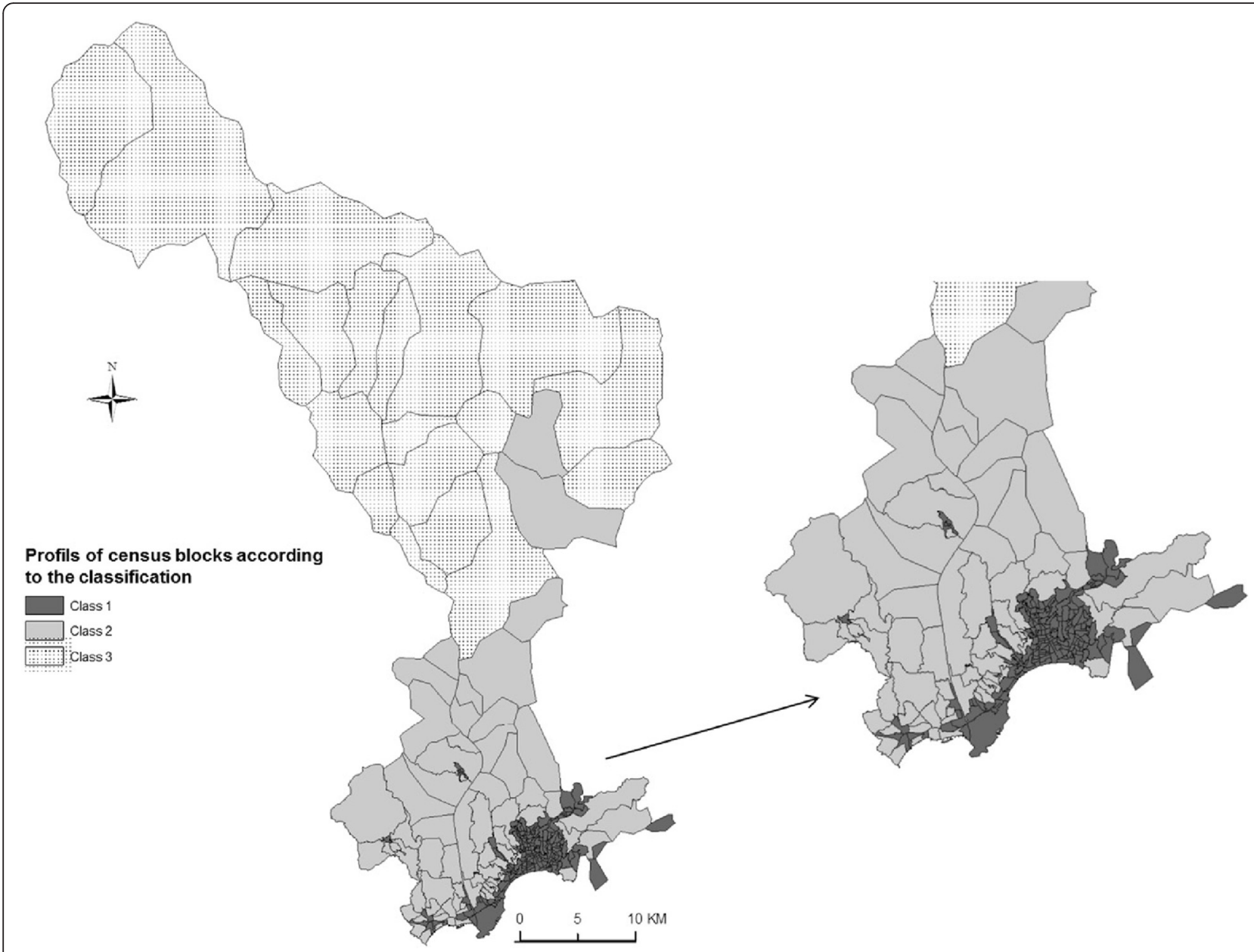

Fig. 3 Spatial distribution of the census blocks profiles in three environmental patterns according to the social, environmental and accessibility of healthcare classification

close to green space too and in the middle class in term of accessibility of healthcare. The environmental pattern 3 encountered only favored very green census blocks but with an unfavorable accessibility to healthcare. The details characteristics of the categories are presented in Table 1.

Table 2 shows the correlation between the geographic indicators: the deprivation index, the proximity to hightraffic roads, the proportion of green space into census blocks and the quantitative measurement of healthcare facilities into census blocks. Deprivation index is significantly and positively correlated to the proximity to hightraffic roads within $150 \mathrm{~m}$ and it is significantly but negatively correlated to the proportion of green space and Distance/Time to healthcare facilities related to mother and newborn. Proximity to high-traffic roads indicator is significantly but negatively correlated to the proportion of green space and it is significantly but positively correlated to the distance/time to healthcare facilities related to mother and newborn. As represented in
Fig. 1, the most deprived neighborhood are located in the urban area of the city of Nice on the coastline, while the most favored neighborhoods are located outside the urban areas in the mountain part of the metropolitan area.

The infant mortality rate is equal to 3.43 per 1000 live births and the neonatal mortality rate is equal to 2.41 per 1000 live births for Nice MA between 2000 and 2012. The relative risks of infant and neonatal mortality according to the level of deprivation index in the census blocks are equal to $\mathrm{RR}=1.1495 \% \mathrm{CI}[1.02 ; 1.27]$ and $\mathrm{RR}$ $=1.1595 \% \mathrm{CI}[1.01 ; 1.32]$ with respected $\mathrm{p}$ values $p=$ 0.026 and $p=0.041$. Table 3 presents the relative risks of infant and neonatal mortality according to the classification of the census blocks taking into account positive and negative environmental exposures, deprivation index and accessibility of healthcare facilities related to mother and newborn. Despite a trend of the infant and neonatal mortality rate between the environmental pattern 1 to the environmental pattern 3 , the $\mathrm{p}$ value $=0.17$ for the 
Table 1 Description of the characteristics of the 3 environmental pattern of census blocks according to their level of environmental exposure, deprivation and accessibility of the nearest healthcare after the classification

\begin{tabular}{|c|c|c|c|c|}
\hline & & \multicolumn{3}{|c|}{ Environmental patterns } \\
\hline & & Pattern $1 \mathrm{~N}=147$ & Pattern $2 N=70$ & Pattern $3 N=19$ \\
\hline \multirow[t]{3}{*}{ Environmental exposure } & $\%$ of green space in a $\mathrm{CB}+$ & $4.35 \pm 11.78^{\mathrm{a}}$ & $37.67 \pm 29.79$ & $84.51 \pm 15.81$ \\
\hline & $\%$ of $C B$ with $10 \mathrm{~m}^{2}$ per habitant & $0 \%$ & $1.43 \%$ & $100 \%$ \\
\hline & $\%$ of CB with habitants living less than $150 \mathrm{~m}$ to roads & $64.63 \%$ & $54.29 \%$ & $5.26 \%$ \\
\hline \multirow[t]{5}{*}{ Accessibility of Healthcare $\dagger$} & Density of specialist/1.000 women & $1.85 \pm 5.92$ & $0.52 \pm 2.41$ & 0 \\
\hline & Distance to healthcare for women (meters) & $1141 \pm 1704$ & $4653 \pm 4511$ & $30334 \pm 15473$ \\
\hline & Distance to healthcare for newborn (meters) & $1168 \pm 1703$ & $6706 \pm 8340$ & $53908 \pm 14877$ \\
\hline & Time to nearest healthcare for women (minute) & $0.94 \pm 1.69$ & $4.87 \pm 5.48$ & $40.79 \pm 16.15$ \\
\hline & Time to nearest healthcare for newborn (minute) & $2.47 \pm 0.62$ & $6.98 \pm 9.43$ & $53.18 \pm 12.60$ \\
\hline \multirow[t]{3}{*}{ Index of deprivation } & $\%$ Low deprived & $6.80 \%$ & $80 \%$ & $68.42 \%$ \\
\hline & $\%$ Middle deprived & $39.46 \%$ & $20 \%$ & $31.58 \%$ \\
\hline & $\%$ High deprived & $53.74 \%$ & $0 \%$ & $0 \%$ \\
\hline \multirow[t]{5}{*}{ Mobility } & $\%$ population who work in the city of residence & $71.41 \pm 15.35$ & $41.38 \pm 21.28$ & $39.83 \pm 23.50$ \\
\hline & $\%$ population who travel by public transport & $23.86 \pm 8.74$ & $6.59 \pm 2.74$ & $4.13 \pm 2.79$ \\
\hline & $\%$ population who travel by foot & $16.05 \pm 9.54$ & $4.55 \pm 3.33$ & $14.69 \pm 12.79$ \\
\hline & $\%$ population who travel by bike & $10.01 \pm 3.84$ & $7.24 \pm 3.75$ & $3.49 \pm 7.09$ \\
\hline & $\%$ population who travel by car & $46.09 \pm 13.62$ & $78.10 \pm 5.99$ & $72.46 \pm 15.05$ \\
\hline
\end{tabular}

$C B$ census blocks

${ }^{\mathrm{a}}$ mean \pm standard deviation

relative risk of infant mortality in the census blocks of the environmental pattern 2 compare to the environmental pattern $1 \mathrm{RR}=0.8395 \% \mathrm{CI}[0.64 ; 1.08]$. However, it should be noted that the number of census blocks by environmental pattern are very small so the significance of the results must be interpreted with caution.

\section{Discussion}

In summary, our investigation conducted at the census blocks level showed that there are environmental inequalities and social inequalities link to infant and neonatal mortality in Nice MA. Moreover, these inequalities are counterbalance by the close proximity of deprived census blocks to healthcare facilities related to mother and newborn. Using GIS for geographic indicators and a combination of MCA and clustering analysis, we identified three environmental patterns which combined multiple factors and how they accumulate in a small area. Despite a significant relation on infant and neonatal mortality risk according to the level of deprivation index, our results did not reveal environmental health inequalities after taking into account the combined effect.

Regarding study strengths, first, the methodology presented here to create classification of the census blocks according to multiple factors could allow us to relatively easily analyze environmental health inequalities. Moreover, similar approaches could be implemented related to; chronic disease which are sensible in the

Table 2 Spearman's Correlation Matrix of geographic indicators at the census blocks (CB) level

\begin{tabular}{|c|c|c|c|c|}
\hline Variables & Deprivation index & Proximity to roads $150 \mathrm{~m}$ & $\begin{array}{l}\text { Proportion of green space } \\
\text { into CB }\end{array}$ & $\begin{array}{l}\text { Quantitative measurement of } \\
\text { healthcare facilities into CB }\end{array}$ \\
\hline Deprivation index & 1 & & & \\
\hline Proximity to roads $150 \mathrm{~m}$ & $0.39^{*}$ & 1 & & \\
\hline Proportion of green space into CB & $-0.61^{*}$ & $-0.33^{*}$ & 1 & \\
\hline $\begin{array}{l}\text { Quantitaive measurement of healthcare } \\
\text { facilities into } C B\end{array}$ & 0.19 & 0.18 & $-0.30^{*}$ & 1 \\
\hline $\begin{array}{l}\text { Distance/time to nearest heathcare } \\
\text { facilities related to newborn }\end{array}$ & $-0.66^{*}$ & $0.48^{*}$ & $0.74^{*}$ & $-0.53^{*}$ \\
\hline $\begin{array}{l}\text { Distance/time to nearest heathcare } \\
\text { facilities related to mother }\end{array}$ & $-0.57^{*}$ & $0.48^{*}$ & $0.77^{*}$ & $-0.45^{*}$ \\
\hline
\end{tabular}

*Bonferroni adjusted significant level $p<0.01$ 
Table 3 Counts, Rate and Relative risk (RR) of Infant and neonatal mortality according to the classification of the census blocks

\begin{tabular}{|c|c|c|c|c|c|c|}
\hline & \multicolumn{3}{|l|}{ Infant Mortality } & \multicolumn{3}{|l|}{ Neonatal Mortality } \\
\hline & Number of cases & Rate & RR [95\% Cl] & Number of cases & Rate & RR $[95 \% \mathrm{Cl}]$ \\
\hline \multicolumn{7}{|c|}{ Environmental patterns } \\
\hline Pattern $1 \mathrm{~N}=147$ & 203 & 3.55 & 1 & 142 & 2.51 & 1 \\
\hline Pattern $2 \mathrm{~N}=70$ & 77 & 3.32 & $0.83[0.64 ; 1.08]$ & 57 & 2.38 & $0.88[0.65 ; 1.20]$ \\
\hline Pattern $3 N=19$ & 4 & 3.01 & $1.17[0.43 ; 3.14]$ & 2 & 1.78 & $0.83[0.21 ; 3.37]$ \\
\hline
\end{tabular}

rate : per 1000 live births

$\mathrm{Cl}$ confidential interval

environmental context as cardiovascular, cancer and diabetes disease or could consider other cities. Second, to our knowledge, this is the first study which simultaneously uses a rich set of geographical indicators as positive and negative environmental exposures, deprivation and accessibility to healthcare facilities according to mother and newborn at the census blocks level to take into account the combined effect on environmental health inequalities. This is an important strength because populations are rarely exposed to a single factor at their place of residence.

Our study has some weakness related to missing integrated information in the classification of the census blocks. Firstly, we are not able to consider living conditions such as the indoor physical environment such as water, sanitation and air quality or housing conditions such as crowding, housing accessibility and safety, thermal comfort (i.e. heat and cold), and energy affordability $[47,48]$. Housing conditions are one of the mechanisms by which social and environmental inequality translates into health inequality [49]. Secondly, we have no data on the estimated or measured dioxide azote $\left(\mathrm{NO}_{2}\right)$, particulate matter (PM) or others air pollution exposure which is likely to represent the largest single environmental health risk, due to adverse births outcomes [50-55]. However, an indicator of proximity to high-traffic roads could be a good proxy of air pollution related to traffic [38]. Thirdly, we could not therefore assess the cumulative negative outdoor exposure with proximity to hightraffic roads, noise, and industrial activity or residential heating due to lack of having no data.

In this study, we adjusted for neighborhood deprivation, but there are additional risk factors hypothesized in the literature for which we unfortunately do not have at the individual-level. Incorporating information from maternal interviews or detailed medical records, which we did not have available for this study, could help control for the potential influence of these factors. For example, birth weight, gestational age, mother's age, and parity of the newborn have been linked with risk of infant mortality. Moreover, some maternal lifestyle behaviors have been linked including the consumption of alcohol, smoking, using drugs, maternal nutritional deficits and access to health care [56-58]. Instead, we considered a deprivation index used in previous articles related on environment health inequalities in France, which is known to be closely related to individual socio economic factors used in studies conducted at fine spatial scale [59].

We know that geographic level is an important consideration in such investigations. The size has to be as small as possible to maximize the homogeneity of specified variables within each area, as well as large differences between areas. In this study we assume the major limitation due to the choice of the geographic level. In fact individual members of a census block all have the average characteristics of the group as whole, when in fact any association observed between variables at the group level does not necessarily mean that the same association exists for an individual plucked from the census block. Due to the ecological design of our study, the results obtained at the census block level cannot be extrapolated to the individual level. Another limitation in our study is the small study population according to the number of the census blocks corresponding on the sample size of the study. We used the smallest spatial level for with socioeconomic variables are routinely available in France.

Investigating associations between the socioeconomic status and the environmental level of exposure have suggested the existence of environmental inequalities. We found that high deprived census blocks were more exposed to air pollution according to the definition of the proximity to the high-traffic roads within a buffer of $150 \mathrm{~m}$ and less exposed to "positive" environmental exposure by definition the proportion of green space or relation to the recommendations the meter square of green space per habitant by census blocks. This result was similar with previous studies in France (Lille, Marseille) which have reported that the most deprived neighborhood are located in census blocks with the highest level of $\mathrm{NO}_{2}$ concentrations [12], in Europe [60, 61], in Canada [62] or in United States [6]. Moreover, regarding residential surrounding greenness and proximity to green spaces, previous studies have reported that individual socioeconomic status could modify the health 
benefits of green spaces [63]. Dadvand et al in 2012, observed a larger benefit of green spaces for pregnant women with lower education qualifications $[64,65]$. In this context, neighborhood socioeconomic status could also have a potential modifying effect on the association between green spaces and health.

We also demonstrated that the level of deprivation of the neighborhood have an impact on the infant and neonatal mortality risk. These finding are coherent with previous literature in France [66] and in other countries [67-69]. The explanations may be that during pregnancy, mothers are likely to face multiple stressful life events, including alone mother, unemployment, and little resources to deal with these socioeconomic conditions $[70,71]$ and parental factors include poor health status (for example, diabetes, obesity and chronic obstructive lung diseases), toxicants such as nicotine, caffeine, cocaine or alcohol $[56,58]$. Previous article demonstrates that the employment status and individual education were strong predictors of spatial behavior related health services [72], individuals overcome spatial access barriers as the ability during pregnancy (individual mobility) and motivation (reasons to visit healthcare services) [73]. Moreover, literature has established that the neighborhood environment of mother and child has an influence on future birth outcomes independently of individual risk factors [74-76].

The major result we found is that despite a significant relation on infant and neonatal mortality risk according to the level of deprivation index, no environmental health inequalities has been revealed after taking into account the combined effect. An important feature of our study was that we assess environmental patterns of census bl0ocks according to the level of socioeconomic, the environmental level of exposure and the accessibility measure to healthcare diagnostics, which are very diverse definition by nature. While the deprived neighborhood in Nice are exposed to higher level of high-traffic roads and lower level of green space, they have higher density and shorter time/distance to gynecologist, obstetrics services, pediatrics and maternity. An English study shows that there is considerable variation in the distances from maternity depending on the geographical location [77], nevertheless population living in deprived neighborhood privileges shorter distance [72]. Centrality is a strong predictor of spatial behavior. Living in center was associated with less distance and time to facilities, an easy access and a higher offer of healthcare facilities for deprived neighborhood.

\section{Conclusion}

Based on neighborhood deprivation, environmental exposure and accessibility to healthcare related to newborn and mother, we identified three environmental patterns at the census block level in Nice metropolitan area. We demonstrate that even if the most deprived census blocks are the most exposed to negative environmental exposure and have a higher risk of neonatal and infant mortality, they have higher availability, an easy accessibility of healthcare and very good transportation networks which allow us to not be exposed to environmental health inequalities. We focused on infant and neonatal mortality, important health indicators of the global health status of population. Quantitative measurements of inequality in geographic accessibility to pediatric care as well as that a mean distance or travel time is very important for priority setting to ensure fair access to facilities related to women and newborn. In this context, our analyses may be useful for influencing urban and public health policies aimed at promoting actions to census blocks identified with needs and their effects on health.

\section{Abbreviations \\ GIS, geographical information system; INSEE, the national institute of statistics and economic studies; IRIS, îlot regroupé pour l'information statistique; MA, metropolitan area; $\mathrm{MCA}$, multiple component analysis; $\mathrm{NO}_{2}$, dioxide azote; PM, particulate matter; WHO, World Health Organization}

\section{Acknowledgements \\ We thank personal of the all the city hall of Nice metropolitan area for their active collaboration when data were collected. We thank the scientific researchers of the Equit'Area project.}

\section{Funding}

This study was supported by the city of Nice for their financial support as a post-doctoral grant.

\section{Availability of data and materials}

Data will not be shared for regulations from the School of public health involved in the research.

\section{Authors' contributions}

C.MP collected the data, performed the statistical analysis, produced the map, conducted the literature review and drafted the article. WK provided rigor methodology and participated in geographical indicators. SP participated in the design of the study. SD, principal investigator of the equit'area project, conceived of the study, participated in its design and coordination. All authors read and approved the final manuscript.

\section{Competing interest}

The authors declare that they have no competing interest.

\section{Consent for publicaton}

Not applicable.

\section{Ethics approval and consent to participate}

Not applicable.

\section{Author details}

${ }^{1}$ Department of Quantitative Methods in Public Health, EHESP School of Public Health, Sorbonne-Paris Cité, 35043 Rennes, France. ${ }^{2}$ Department of Environmental and Occupational Health, EHESP School of Public Health, Sorbonne-Paris Cité, 35043 Rennes, France. ${ }^{3}$ INSERM U1085-IRSET - Research institute of environmental and occupational health, Rennes, France. ${ }^{4}$ UMR ESPACE 7300, University of Nice Sophia, Nice, France.

Received: 12 March 2016 Accepted: 30 June 2016

Published online: 22 July 2016 


\section{References}

1. Ministère de l'Environnement, de l'Energie et de la Mer. 2e Plan National Santé Environnement 2009-2013 - [Internet]. [cited 2016 Jul 12]. Available from: http://www.developpement-durable.gouv.fr/-2e-Plan-National-Santehtml.

2. Assessment Report; $\mathrm{WHO}$. Environmental Health Inequalities in Europe. [Internet]. WHO. [cited 2015 Nov 25]. Available from: [http://www.euro.who. int/_data/assets/pdf_file/0010/157969/e96194.pdf].

3. Braubach M. Benefits of environmental inequality assessments for action. J Epidemiol Community Health. 2013;67:625-8.

4. Deguen S, Zmirou-Navier D. Social inequalities resulting from health risks related to ambient air quality-A European review. Eur J Public Health. 2010;20: 27-35.

5. Briggs D, Abellan JJ, Fecht D. Environmental inequity in England: small area associations between socio-economic status and environmental pollution. Soc Sci Med 1982. 2008;67:1612-29.

6. Yanosky JD, Schwartz J, Suh HH. Associations between measures of socioeconomic position and chronic nitrogen dioxide exposure in Worcester, Massachusetts. J Toxicol Environ Health A. 2008;71:1593-602.

7. Diekmann A, Meyer R. Kolner Z Soziol Sozialpsychologie. 2010;62:437.

8. Viel J-F, Hägi M, Upegui E, Laurian L. Environmental justice in a French industrial region: Are polluting industrial facilities equally distributed? Health Place. 2011:17:257-62.

9. Brochu PJ, Yanosky JD, Paciorek CJ, Schwartz J, Chen JT, Herrick RF, et al. Particulate air pollution and socioeconomic position in rural and urban areas of the Northeastern United States. Am J Public Health. 2011;101 Suppl 1:S224-30.

10. Bell ML, Ebisu K. Environmental inequality in exposures to airborne particulate matter components in the United States. Environ Health Perspect. 2012;120:1699-704.

11. Laurian L, Funderburg R. Environmental justice in France? A spatio-temporal analysis of incinerator location. J Environ Plan Manag. 2014;57:424-46.

12. Padilla CM, Kihal-Talantikite W, Vieira VM, Rossello P, Nir GL, Zmirou-Navier $D$, et al. Air quality and social deprivation in four French metropolitan areas-A localized spatio-temporal environmental inequality analysis. Environ Res. 2014;134:315-24.

13. Mitchell R, Popham F. Effect of exposure to natural environment on health inequalities: an observational population study. Lancet Lond Engl. 2008;372: 1655-60.

14. Lee ACK, Maheswaran R. The health benefits of urban green spaces: a review of the evidence. J Public Health Oxf Engl. 2011;33:212-22.

15. Bowler DE, Buyung-Ali LM, Knight TM, Pullin AS. A systematic review of evidence for the added benefits to health of exposure to natural environments. BMC Public Health. 2010;10:456.

16. OECD. Infant mortality rates [Internet]. OECD Publishing; 2014. Available from: https://data.oecd.org/healthstat/infant-mortality-rates.htm

17. Lawn JE, Cousens S, Zupan J. Lancet Neonatal Survival Steering Team. 4 million neonatal deaths: when? Where? Why? Lancet Lond Engl. 2005;365: 891-900.

18. Gabrysch S, Campbell OMR. Still too far to walk: literature review of the determinants of delivery service use. BMC Pregnancy Childbirth. 2009;9:34.

19. Paez A, Mercado RG, Farber S, Morency C, Roorda M. Accessibility to health care facilities in Montreal Island: an application of relative accessibility indicators from the perspective of senior and non-senior residents. Int J Health Geogr. 2010;9:52.

20. Salze P, Banos A, Oppert J-M, Charreire H, Casey R, Simon C, et al. Estimating spatial accessibility to facilities on the regional scale: an extended commutingbased interaction potential model. Int J Health Geogr. 2011;10:2.

21. Bryce J, Boschi-Pinto C, Shibuya K, Black RE, WHO Child Health Epidemiology Reference Group. WHO estimates of the causes of death in children. Lancet Lond Engl. 2005;365:1147-52.

22. Black RE, Cousens S, Johnson HL, Lawn JE, Rudan I, Bassani DG, et al. Global, regional, and national causes of child mortality in 2008: a systematic analysis. Lancet Lond Engl. 2010;375:1969-87.

23. Whitehouse CR. The health of children. A review of research on the place of health in cycles of disadvantage. J R Coll Gen Pract. 1982;32:249.

24. Barker DJP. The origins of the developmental origins theory. J Intern Med. 2007:261:412-7.

25. Heindel JJ, Balbus J, Birnbaum L, Brune-Drisse MN, Grandjean P, Gray K, et al. Developmental Origins of Health and Disease: Integrating Environmental Influences. Endocrinology. 2015;156:3416-21.
26. Maroziene L, Grazuleviciene R. Maternal exposure to low-level air pollution and pregnancy outcomes: a population-based study. Environ Health Glob Access Sci Source. 2002;1:6

27. Slama R, Thiebaugeorges O, Goua V, Aussel L, Sacco P, Bohet A, et al. Maternal personal exposure to airborne benzene and intrauterine growth. Environ Health Perspect. 2009:117:1313-21.

28. Grzybowski S, Stoll K, Kornelsen J. Distance matters: a population based study examining access to maternity services for rural women. BMC Health Serv Res. 2011;11:147.

29. Parker L, Dickinson HO, Morton-Jones T. Proximity to maternity services and stillbirth risk. Arch Dis Child Fetal Neonatal Ed. 2000;82:F167-8.

30. Blondel B, Drewniak N, Pilkington H, Zeitlin J. Out-of-hospital births and the supply of maternity units in France. Health Place. 2011;17:1170-3.

31. Jones $P$, Alberti C, Julé L, Chabernaud J-L, Lodé N, Sieurin A, et al. Mortality in out-of-hospital premature births. Acta Paediatr Oslo Nor 1992. 2011:100:181-7.

32. Graham WJ, Varghese B. Quality, quality, quality: gaps in the continuum of care. Lancet Lond Engl. 2012;379:e5-6.

33. Gray R, Bonellie SR, Chalmers J, Greer I, Jarvis S, Kurinczuk JJ, et al. Contribution of smoking during pregnancy to inequalities in stillbirth and infant death in Scotland 1994-2003: retrospective population based study using hospital maternity records. BMJ. 2009:339:b3754. doi:10.1136/bmj. b3754.:b3754

34. Deguen S, Lalloue B, Bard D, Havard S, Arveiler D, Zmirou-Navier D. A smallarea ecologic study of myocardial infarction, neighborhood deprivation, and sex: a Bayesian modeling approach. Epidemiology. 2010;21:459-66.

35. Deguen S, Petit C, Delbarre A, Kihal W, Padilla C, Benmarhnia T, et al. Neighbourhood Characteristics and Long-Term Air Pollution Levels Modify the Association between the Short-Term Nitrogen Dioxide Concentrations and All-Cause Mortality in Paris. PLoS One. 2015;10:e0131463.

36. Kihal-Talantikite W, Padilla CM, Lalloue B, Rougier C, Defrance J, ZmirouNavier D, et al. An exploratory spatial analysis to assess the relationship between deprivation, noise and infant mortality: an ecological study. Environ Health Glob Access Sci Source. 2013;12:109.

37. Lalloué B, Monnez J-M, Padilla C, Kihal W, Le Meur N, Zmirou-Navier D, et al. A statistical procedure to create a neighborhood socioeconomic index for health inequalities analysis. Int J Equity Health. 2013:12:21.

38. Beckerman B, Jerrett M, Brook JR, Verma DK, Arain MA, Finkelstein MM. Correlation of nitrogen dioxide with other traffic pollutants near a major expressway. Atmos Environ. 2008;42:275-90.

39. CERTU- Centre d'études sur les réseaux de transport et l'urbanisme. La dispersion des polluants aux abords des infrastructures routières [Internet]fiche CERTU N² - Juin 2009. Available from: http://www.bv.transports.gouv. qc.ca/mono/1029473/02_Fiche_2.pd

40. CORINE Land Cover (CLC) : données statistiques [Données] : Observation et statistiques [Internet]. [cited 2016 Feb 23]. Available from: http://www. statistiques.developpement-durable.gouv.fr/donnees-ligne/t/donnees.html?tx_ ttnews\%5Btt news\%5D=24275\&cHash=fc83c4f9bef57fb40874fde73387da4c

41. Bixby H, Hodgson S, Fortunato L, Hansell A, Fecht D. Associations between Green Space and Health in English Cities: An Ecological, Cross-Sectional Study. PLoS ONE. 2015;10(3):e0119495.

42. Kihal-Talantikite W, Padilla CM, Lalloué B, Gelormini M, Zmirou-Navier D, Deguen S. Green space, social inequalities and neonatal mortality in France. BMC Pregnancy Childbirth. 2013;13:191.

43. Ministre délégué auprès du premier ministre chargé de la protection de la nature et de l'environnement. Circulaire du 8 février 1973 relative à la politique d'espaces verts. [Internet]. Journal officiel de la république française.; 1973. Available from: http://data0.eklablog.com/sociotopes/perso/ documents/ circulaire\%20du\%208\%20fevrier\%20relative\%20a\%20la\%20politiqu.pdf

44. Bouge F. Caracterisation des espaces verts publics en fonction de leur place dans le gradient urbain-rural. Rapport on Internet. 2009. Available from: http://www.applis.univ-tours.fr/scd/EPU DA/2009PFE Bouge_Felix.pdf.

45. Hastie T, Tibshirani R, Friedman J. The Elements of Statistical Learning [Internet]. New York: Springer New York; 2009. [cited 2016 Feb 23], Available from: http://link.springer.com/10.1007/978-0-387-84858-7.

46. Husson F, Josse J, Le S, Mazet J. FactoMineR: Multivariate Exploratory Data Analysis and Data Mining [Internet]. 2015 [cited 2015 Oct 19]. Available from: https://cran.r-project.org/web/packages/FactoMineR/index.html

47. Kohlhuber M, Mielck A, Weiland SK, Bolte G. Social inequality in perceived environmental exposures in relation to housing conditions in Germany. Environ Res. 2006;101:246-55. 
48. Braubach M, Fairburn J. Social inequities in environmental risks associated with housing and residential location - a review of evidence. Eur J Public Health. 2010;20:36-42.

49. Public Health, Environmental and Social Determinants of Health, WHO Tackling health inequalities by improving the quality of housing From evidence to action. [Internet]. WHO. [cited 2015 Nov 25]. Available from: http://www.who.int/phe/news/aug-sept2015/en/

50. Woodruff TJ, Darrow LA, Parker JD. Air pollution and postneonatal infant mortality in the United States, 1999-2002. EnvironHealth Perspect. 2008;116: 110-5.

51. Brauer M, Lencar C, Tamburic L, Koehoorn M, Demers P, Karr C. A cohort study of traffic-related air pollution impacts on birth outcomes. Environ Health Perspect. 2008;116:680-6.

52. Shah PS, Balkhair T. Air pollution and birth outcomes: A systematic review. Environ Int. 2011;37:498-516.

53. Dadvand P, Parker J, Bell ML, Bonzini M, Brauer M, Darrow LA, et al. Maternal exposure to particulate air pollution and term birth weight: a multi-country evaluation of effect and heterogeneity. Environ Health Perspect. 2013;121: 267-373.

54. Kaiser R, Romieu I, Medina S, Schwartz J, Krzyzanowski M, Künzli N. Air pollution attributable postneonatal infant mortality in U.S. metropolitan areas: a risk assessment study. Environ Health Glob Access Sci Source. 2004;3:4.

55. Barnett AG, Plonka K, Seow WK, Wilson L-A, Hansen C. Increased traffic exposure and negative birth outcomes: a prospective cohort in Australia. Environ Health. 2011;10:26

56. Patra J, Bakker R, Irving H, Jaddoe WW, Malini S, Rehm J. Dose-response relationship between alcohol consumption before and during pregnancy and the risks of low birthweight, preterm birth and small for gestational age (SGA)-a systematic review and meta-analyses. BJOG Int J Obstet Gynaecol. 2011;118:1411-21.

57. O'Leary CM, Nassar N, Kurinczuk JJ, Bower C. The effect of maternal alcohol consumption on fetal growth and preterm birth. BJOG Int J Obstet Gynaecol. 2009;116:390-400.

58. Crane JMG, Keough M, Murphy P, Burrage L, Hutchens D. Effects of environmental tobacco smoke on perinatal outcomes: a retrospective cohort study. BJOG Int J Obstet Gynaecol. 2011;118:865-71.

59. Greenland S. Ecologic versus individual-level sources of bias in ecologic estimates of contextual health effects. Int J Epidemiol. 2001:30:1343-50.

60. Kruize H, Driessen PPJ, Glasbergen P, van Egmond KND. Environmental equity and the role of public policy: experiences in the Rijnmond region. Environ Manage. 2007;40:578-95.

61. Namdeo A, Stringer C. Investigating the relationship between air pollution, health and social deprivation in Leeds. UK Environ Int. 2008;34:585-91.

62. Crouse DL, Ross NA, Goldberg MS. Double burden of deprivation and high concentrations of ambient air pollution at the neighbourhood scale in Montreal, Canada. Soc Sci Med. 2009;69(6):971-81.

63. de Vries S, Verheij RA, Groenewegen PP, Spreeuwenberg P. Natural Environments-Healthy Environments? An Exploratory Analysis of the Relationshp between Greenspace and Health. Environ Plan A. 2003;35: 1717-31.

64. Dadvand P, de Nazelle A, Figueras F, Basagaña X, Su J, Amoly E, et al. Green space, health inequality and pregnancy. Environ Int. 2012;40:110-5.

65. Dadvand P, Sunyer J, Basagaña X, Ballester F, Lertxundi A, FernándezSomoano A, et al. Surrounding greenness and pregnancy outcomes in four Spanish birth cohorts. Environ Health Perspect. 2012;120:1481-7.

66. Padilla C, Lalloué B, Pies C, Lucas E, Zmirou-Navier D, Deguen S. An Ecological Study to Identify Census Blocks Supporting a Higher Burden of Disease: Infant Mortality in the Lille Metropolitan Area, France. Matern Child Health J. 2013:18:171-179.

67. Elo I, Culhane J, Kohler I, O'Campo P, Burke J, Messer L, et al. Neighbourhood deprivation and small-for-gestational-age term births in the United States. Paediatr Perinat Epidemiol. 2009;23:87-96.

68. Zeka A, Melly S, Schwartz J. The effects of socioeconomic status and indices of physical environment on reduced birth weight and preterm births in Eastern Massachusetts. Environ Health Glob Access Sci Source. 2008;7:60.

69. Blumenshine P, Egerter S, Barclay CJ, Cubbin C, Braveman PA. Socioeconomic disparities in adverse birth outcomes: a systematic review. Am J Prev Med. 2010;39:263-72.

70. Miranda ML, Maxson P, Edwards S. Environmental Contributions to Disparities in Pregnancy Outcomes. Epidemiol Rev. 2009:31:67-83.
71. Nkansah-Amankra S, Luchok KJ, Hussey JR, Watkins K, Liu X. Effects of maternal stress on low birth weight and preterm birth outcomes across neighborhoods of South Carolina, 2000-2003. Matern Health J. 2010;14:215-26.

72. Perchoux C, Kestens $Y$, Thomas F, Hulst AV, Thierry B, Chaix B. Assessing patterns of spatial behavior in health studies: Their socio-demographic determinants and associations with transportation modes (the RECORD Cohort Study). Soc Sci Med. 2014;119:64-73.

73. Brondeel R, Weill A, Thomas F, Chaix B. Use of healthcare services in the residence and workplace neighbourhood: the effect of spatial accessibility to healthcare services. Health Place. 2014;30:127-33.

74. Luo Z-C, Wilkins R, Kramer MS. Effect of neighbourhood income and maternal education on birth outcomes: a population-based study. CMAJ. 2006:174:1415-20.

75. Genereux M, Auger N, Goneau M, Daniel M. Neighbourhood socioeconomic status, maternal education and adverse birth outcomes among mothers living near highways. JE pidemiol Community Health. 2008;62:695-700.

76. Zeitlin J, Combier E, Levaillant M, Lasbeur L, Pilkington $\mathrm{H}$, Charreire $\mathrm{H}$, et al. Neighbourhood socio-economic characteristics and the risk of preterm birth for migrant and non-migrant women: a study in a French district. Paediatr Perinat Epidemiol. 2011;25:347-56.

77. Propper C, Damiani M, Leckie G, Dixon J. Impact of patients' socioeconomic status on the distance travelled for hospital admission in the English National Health Service. J Health Serv Res Policy. 2007;12:153-9.

\section{Submit your next manuscript to BioMed Central and we will help you at every step:}

- We accept pre-submission inquiries

- Our selector tool helps you to find the most relevant journal

- We provide round the clock customer support

- Convenient online submission

- Thorough peer review

- Inclusion in PubMed and all major indexing services

- Maximum visibility for your research

Submit your manuscript at www.biomedcentral.com/submit 